\title{
Ultrasonographic evaluation and comparison of articular cartilage of the femur condyles between the limbs in patients with an elevated $Q$ angle
}

\author{
DOI: https://doi.org/10.5114/pq.2018.75995
}

\author{
Maciej Kusiak, Adam Kawczyński \\ University School of Physical Education in Wrocław, Wrocław, Poland
}

\begin{abstract}
Introduction. TPatellofemoral pain may be caused by an increase of the pressure of the joint surfaces in the patella and the femur, and, as a consequence, a premature abrasion of joint cartilage. The aim of the study was an ultrasonographic evaluation and comparison of articular cartilage of the femur condyles between the limbs in patients with an elevated $Q$ angle.

Methods. The total of 13 women aged $35-45$ years with the $Q$ angle exceeding $15^{\circ}$ took part in the research. The measurement of the $Q$ angle was carried out with a goniometer. The thickness of joint cartilage was measured with the ultrasound scanner HONDA HS-2200. Shapiro-Wilk test for normality was applied. The variance test ANOVA for independent samples allowed to evaluate the differences of the measured parameters. The Bonferroni test was applied for multiple comparison.

Results and conclusions. The analysis did not depict any statistically significant differences in the thickness of cartilage of the lateral condyle $(p=0.83)$ or the medial condyle $(p=0.12)$, or in the $Q$ angle $(p=1.00)$ between the right and left limb. The changes in thickness of the joint cartilage covering the lateral and medial condyles occurred symmetrically in both limbs. Key words: joint cartilage, $Q$ angle, patellofemoral joint
\end{abstract}

\section{Introduction}

Patellofemoral pain is one of the problems affecting the knee joint that appear in clinical practice. According to the previous research, it more often concerns physically active patients [1-4] and women [5].

The reason for pain in the front part of the joint is multifactorial. The direct determinants are mainly the injury and damage of the joint structures. However, when no injury is responsible for the damage, pain results mainly from an increase of the pressure of the joint surfaces in the patella and the femur, and, as a consequence, a premature abrasion of joint cartilage [6-10]. The patella is a sesamoid for the quadriceps femoris muscle. It increases the strength of its movement while the knee straightens up [11]. In this way, it carries significant forces, reaching up to $1 / 2$ of the body mass while walking [12] and exceeding 7 times the body mass while crouching [13].

The $Q$ angle determines the direction of the force movement of the quadriceps femoris in the knee joint. It lies between the line from the anterior superior iliac spine (ASIS) to the centre of the patella and the line from the centre of the patella to the tuberosity of tibia [14]. The value of the $Q$ angle above $15-20^{\circ}$ is generally considered to cause malfunction of the extensor apparatus of the knee and patellofemoral pain [15-21]. Some authors also point at an increased risk of occurrence of chondromalacia patellae [22-24], as well as the dislocation and subluxation of the patella [25-29].

The aim of the study was an ultrasonographic evaluation and comparison of articular cartilage of the femur condyles between the limbs in patients with an elevated $Q$ angle.

\section{Subjects and methods}

\section{Subjects}

The total of 22 healthy women aged $35-45$ years volunteered for the study. After $\mathrm{Q}$ angle measurement, they were qualified for testing $\left(Q\right.$ angle $\left.>15^{\circ}\right)$. Out of these, 13 women took part in the research (average age $\pm S D, 42 \pm 3.7$ years). The determined values (average $\pm S D$ ) of height, weight, and BMI were, respectively, as follows: $1.66 \pm 0.09 \mathrm{~m}, 56.77 \pm$ $6.87 \mathrm{~kg}, 20.65 \pm 3.1 \mathrm{~kg} / \mathrm{m}^{2}$. The analysis referred to both $\mathrm{knee}$ joints. The value (average $\pm S D$ ) of the $Q$ angle in the examined joints was $23.6 \pm 3^{\circ}$. The criteria excluding from the research were: an injury in the area of the knee joint, surgical intervention, and pain affecting the joint for the previous 4 weeks.

The participants of the research were informed about its purpose and took part in it voluntarily.

\section{Methods}

A goniometer was used to measure the $Q$ angle. The measurement was performed in the back lying position with a straightened knee joint and totally relaxed quadriceps femoris muscle. A washable marker was used to indicate the approximate points of placing the goniometer: the ASIS, the centre of the patella, and the tuberosity of tibia. The examined limb was placed perpendicularly to the surface of the bed on which the subject was lying (the line going through the centre of the heel and the second toe was perpendicular to the surface of the table). The measurement was carried out for both limbs. All measurements were performed by the same person.

Correspondence address: Maciej Kusiak, Katedra Sportu Paraolimpijskiego, Akademia Wychowania Fizycznego,

al. I.J. Paderewskiego 35, 51-612 Wrocław, Poland, e-mail: maciejkusiak89@gmail.com

Received: 01.12 .2017

Accepted: 06.02.2018

Citation: Kusiak M, Kawczyński A. Ultrasonographic evaluation and comparison of articular cartilage of the femur condyles between the limbs in patients with an elevated Q angle. Physiotherapy Quarterly. 2018;26(2):19-22; doi: https://doi.org/10.5114/pq.2018.75995. 


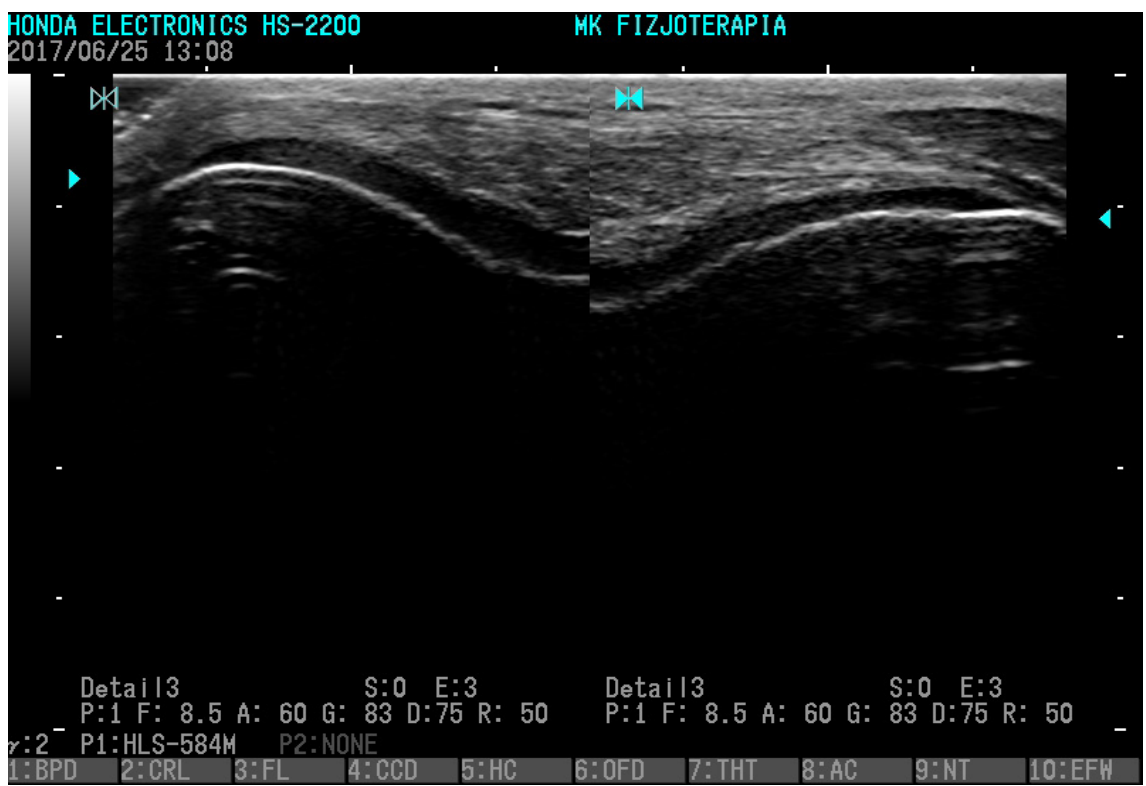

Figure 1. An ultrasound scanner image depicting the layer of joint cartilage on the femur condyles

The thickness of the joint cartilage covering the lateral and medial condyle of the femur was measured with the use of an ultrasound scanner HONDA HS-2200 with a line probe HLS - 584M, 6.0-8.5-11.00 MHz (Honda, Japan). The knee joint was put into maximal flexion. The line probe was placed horizontally, right above the patella, perpendicularly to the surface of the condyles of femur. The thickness of the homogeneous and the low- or non-feature structure of the cartilage was measured on the transmitted image; the software of the ultrasound scanner was applied (Figure 1). The method is characterized by a good reproducibility in the measurement of the thickness of joint cartilage covering the lateral and medial condyle of the femur [30]. The measurement was carried for both limbs. All measurements were performed by the same person.

\section{Statistical analysis}

The statistical analysis was carried out with the application of the Statistica 13.1 software. The Shapiro-Wilk test allowed to prove a normal data distribution. The variance test ANOVA for independent samples was used to evaluate the differences of the measured parameters. The Bonferroni test was applied for the multiple comparison. The diversification of the measured parameters was considered to be significant at the level of $p<0.05$.

\section{Ethical approval}

The research related to human use has been complied with all the relevant national regulations and institutional policies, has followed the tenets of the Declaration of Helsinki, and has been approved by the Ethical Committee of the University School of Physical Education in Wrocław, Poland.

\section{Informed consent}

Informed consent has been obtained from all individuals included in this study.

\section{Results}

The thickness of joint cartilage of the surface of the medial femur condyle and lateral femur condyle, as well as the $Q$ angle determined for the left and right knee joints are
Table 1. Thickness of joint cartilage of the lateral and medial condyles and the $Q$ angle for the right and left limb

\begin{tabular}{|l|c|c|}
\hline \multirow{2}{*}{ Parameter } & \multicolumn{2}{|c|}{ Lower limb (average $\pm S D)$} \\
\cline { 2 - 3 } & Left $(n=13)$ & Right $(n=13)$ \\
\hline LFC thickness $[\mathrm{mm}]$ & $1.57 \pm 0.22$ & $1.59 \pm 0.28$ \\
\hline MFC thickness $[\mathrm{mm}]$ & $2.04 \pm 0.25$ & $2.23 \pm 0.37$ \\
\hline Q angle $\left[{ }^{\circ}\right]$ & $23.6 \pm 3.07$ & $23.6 \pm 3.07$ \\
\hline
\end{tabular}

LFC - lateral femur condyle, MFC - medial femur condyle

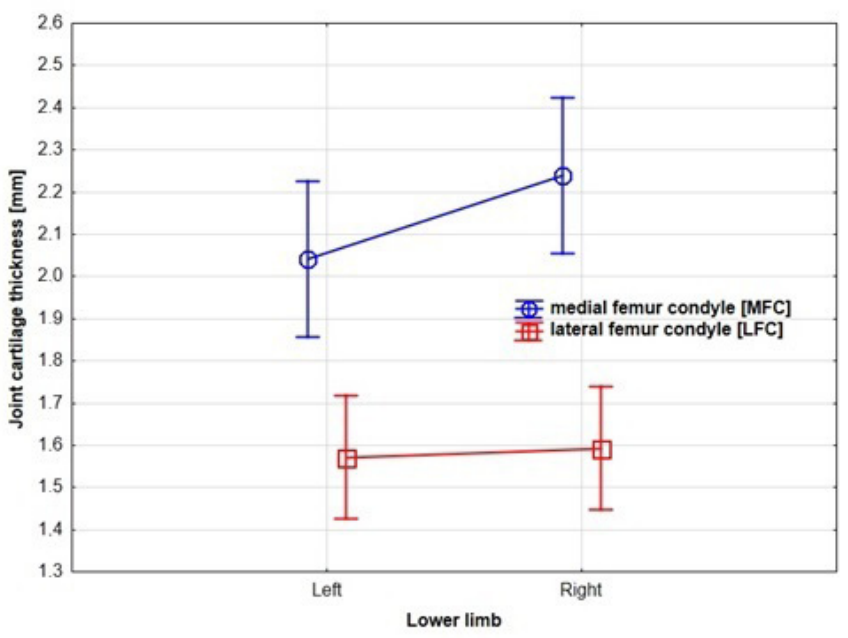

Figure 2. Thickness of joint cartilage of the medial and lateral condyles in both limbs

The undertaken analysis did not depict any statistically significant difference in the thickness of joint cartilage of the lateral femur condyle $(p=0.83)$ or medial femur condyle $(p=0.12)$ (Figure 2$)$, or in the $Q$ angle $(p=1.00)$ between the right and left limb in the examined women.

\section{Discussion}

The authors of other studies concerning the value of the $Q$ angle in the knee joint most often delineate data for a single person [31, 32] or a group of people [33-36]. Measurement is sometimes limited only to the right $\operatorname{limb}[37,38]$ or the $\operatorname{limb}$ 
affected by symptoms [39]. Hvid et al. [32] provide information about symmetrical occurrence of the $Q$ angle in both limbs; 29 men and women with patella pain took part in the research, and no differences in the $Q$ angle for the right and left limb for any examined person were found. Neither did Messier et al. [40] depict any statistically significant differences between the sides in their study involving a 16-person group. It is important to remember, though, that the $Q$ angle may individually occur asymmetrically [41]. We suggest that data for both limbs should be gathered for scientific purposes, and the obtained results be interpreted not only in reference to group analyses, but in some cases individually as well.

\section{Limitations}

One of the limitations of the study is a small size of the group. In further research, the investigated group should be expanded. Secondly, most of the earlier studies on the $Q$ angle date back to the 1980s and 1990s. Currently, there are no references to the results of the influence of the $Q$ angle on the knee joint structure evaluated by imaging examinations. Thirdly, the $\mathrm{Q}$ angle and the position of the patella in the joint also depend on other factors, such as femoral anteversion, width of the pelvis, and other anthropometrical parameters, tension of the patella retinaculums, or tension of the knee ligaments. These factors must be taken into account in advancing the clinical implications of the results.

\section{Conclusions}

Changes in the thickness of joint cartilage covering the lateral and medial condyles occur symmetrically in both limbs among women aged 35-45 years with the $Q$ angle > $15^{\circ}$. No statistically significant differences in the value of the $Q$ angle between the right and left side were depicted.

\section{Disclosure statement}

No author has any financial interest or received any financial benefit from this research.

\section{Conflict of interest}

The authors state no conflict of interest.

\section{References}

1. Clement DB, Taunton JE, Smart GW, McNichol KL. A survey of overuse running injuries. Phys Sportsmed. 1981; 9(5):47-58; doi: 10.1080/00913847.1981.11711077.

2. Devereaux MD, Lachmann SM. Patello-femoral arthralgia in athletes attending a sports injury clinic. $\mathrm{Br} \mathrm{J}$ Sports Med. 1984;18(1):18-21; doi: 10.1136/bjsm.18.1.18.

3. Jordaan G, Schwellnus MP. The incidence of overuse injuries in military recruits during basic military training. Mil Med. 1994;159(6):421-426; doi:10.1093/milmed/159.6.421.

4. Renström AF. Knee pain in tennis players. Clin Sports Med. 1995;14(1):163-175.

5. Boling M, Padua D, Marshall S, Guskiewicz K, Pyne S, Beutler A. Gender differences in the incidence and prevalence of patellofemoral pain syndrome. Scand J Med Sci Sports. 2010;20(5):725-730; doi: 10.1111/j.1600-0838. 2009.00996.x.

6. Fulkerson JP, Shea KP. Mechanical basis for patellofemoral pain and cartilage breakdown. In: Ewing JW (ed.), Articular cartilage and knee joint function: basic science and arthroscopy. New York: Raven Press; 1990; 93-101.

7. Heino Brechter J, Powers CM. Patellofemoral stress during walking in persons with and without patellofemoral pain. Med Sci Sports Exerc. 2002;34(10):15821593; doi: 10.1249/01.MSS.0000035990.28354.c6.

8. Herzog W, Diet S, Suter E, Mayzus P, Leonard TR, Müller $\mathrm{C}$, et al. Material and functional properties of articular cartilage and patellofemoral contact mechanics in an experimental model of osteoarthritis. J Biomech. 1998;31(12): 1137-1145; doi: 10.1016/S0021-9290(98)00136-5.

9. Møller BN, Møller-Larsen F, Frich LH. Chondromalacia induced by patellar subluxation in the rabbit. Acta Orthop Scand. 1989;60(2):188-191; doi: 10.3109/1745367890 9149251.

10. Sanchis-Alfonso V, Rosello-Sastre E, Martinez-Sanjuan V. Pathogenesis of anterior knee pain syndrome and functional patellofemoral instability in the active young. Am J Knee Surg. 1999;12(1):29-40.

11. Yamaguchi GT, Zajac FE. A planar model of the knee joint to characterize the knee extensor mechanism. J Biomech. 1989;22(1):1-10; doi: 10.1016/0021-9290(89) 90179-6.

12. Reilly DT, Martens M. Experimental analysis of the quadriceps muscle force and patello-femoral joint reaction force for various activities. Acta Orthop Scand. 1972; 43(2):126-137; doi: 10.3109/17453677208991251.

13. Mason JJ, Leszko F, Johnson T, Komistek RD. Patellofemoral joint forces. J Biomech. 2008;41(11):2337-2348; doi: 10.1016/j.jbiomech.2008.04.039.

14. Hungerford DS, Barry M. Biomechanics of the patellofemoral joint. Clin Orthop Relat Res. 1979;144:9-15; doi: 10.1097/00003086-197910000-00003.

15. Beck JL, Wildermuth BP. The female athlete's knee. Clin Sports Med. 1985;4(2):345-366.

16. Ciullo JV. Lower extremity injuries. In: Pearl AJ (ed.), The athletic female. Champaign: Human Kinetics Publishers; 1993; 267-298.

17. Guerra JP, Arnold MJ, Gajdosik RL. Q angle: Effects of isometric quadriceps contraction and body position. J Orthop Sports Phys Ther. 1994;19(4):200-204; doi: 10.2519/jospt.1994.19.4.200.

18. Hunter-Griffin LY. Aspects of injuries to the lower extremity unique to the female athlete. In: Nicholas JA, Hershman EB (eds.), The lower extremity and spine in sports medicine. St. Louis: Mosby; 1995; 141-157.

19. Malek MM, Mangine RE. Patellofemoral pain syndromes: a comprehensive and conservative approach. J Orthop Sports Phys Ther. 1981;2(3):108-116; doi: 10.2519/ jospt.1981.2.3.108.

20. Paulos L, Rusche K, Johnson C, Noyes FR. Patellar malalignment: a treatment rationale. Phys Ther. 1980;60(12): 1624-1632; doi: 10.1093/ptj/60.12.1624.

21. Percy EC, Strother RT. Patellalgia. Phys Sportsmed. 1985; 13(7):43-59; doi: 10.1080/00913847.1985.11708831.

22. Brody DM. Running injuries. Clin Symp. 1980;32(4):2-36.

23. Hoerner TE. Injuries of the lower extremities. In: Vinger PF, Hoerner EF (eds.), Sports injuries: the unthwarted epidemic. Littleton: PSG Publishing; 1986; 235-249.

24. Huberti HH, Hayes WC. Patellofemoral contact pressures: the influence of Q-angle and tendofemoral contact. J Bone Joint Surg. 1984;66(5):715-724; doi: 10.2106/ 00004623-198466050-00010.

25. Moskwa CA, Nicholas JA, Goldberg B. Musculoskeletal risk factors in the young athlete. Phys Sportsmed. 1989; 17(11):49-59; doi: 10.1080/00913847.1989.11709911.

26. Papagelopoulos PJ, Sim FH. Patellofemoral pain syndrome: diagnosis and management. Orthopedics. 1997; 20(2):148-157; doi: 10.3928/0147-7447-19970201-12. 
27. Strizak AM. Knee injuries. In: Nicholas JA, Hershman EB (eds.), The lower extremity and spine in sports medicine. St. Louis: Mosby; 1995; 1251-1275.

28. Zimbler S, Smith J, Scheller A, Banks HH. Recurrent subluxation and dislocation of the patella in association with athletic injuries. Orthop Clin North Am. 1980;11(4):755770.

29. Van Holsbeeck M, Introcaso J. Musculoskeletal ultrasound. St. Louis: Mosby; 2001.

30. Naredo E, Acebes C, Möller I, Canillas F, de Agustín JJ, de Miguel E, et al. Ultrasound validity in the measurement of knee cartilage thickness. Ann Rheum Dis. 2009;68(8): 1322-1327; doi: 10.1136/ard.2008.090738.

31. Brown DE, Alexander AH, Lichtman DM. The ElmslieTrillat procedure: evaluation in patellar dislocation and subluxation. Am J Sports Med. 1984;12(2):104-109; doi: $10.1177 / 036354658401200203$.

32. Hvid I, Andersen LI, Schmidt H. Chondromalacia patellae. The relation to abnormal patellofemoral joint mechanics. Acta Orthop Scand. 1981;52(6):661-666; doi: 10.3109/ 17453678108992164.

33. Aglietti P, Insall JN, Cerulli G. Patellar pain and incongruence. I: Measurements of incongruence. Clin Orthop Relat Res. 1983;176:217-224.

34. Boucher JP, King MA, Lefebvre R, Pépin A. Quadriceps femoris muscle activity in patellofemoral pain syndrome. Am J Sports Med. 1992;20(5):527-532; doi: 10.1177/ 036354659202000507.

35. Caylor D, Fites R, Worrell TW. The relationship between quadriceps angle and anterior knee pain syndrome. J Orthop Sports Phys Ther. 1993;17(1):11-16; doi: 10.2519/ jospt.1993.17.1.11.

36. Cowan DN, Jones BH, Frykman PN, Polly DW, Harman EA, Rosenstein RM, et al. Lower limb morphology and risk of overuse injury among male infantry trainees. Med Sci Sports Exerc. 1996;28(8):945-952; doi: 10.1097/00005768-199608000-00002.

37. Guerra JP, Arnold MJ, Gajdosik RL. Q angle: effects of isometric quadriceps contraction and body position. $J$ Orthop Sports Phys Ther. 1994;19(4):200-204; doi: 10.2519/jospt.1994.19.4.200.

38. Woodland LH, Francis RS. Parameters and comparisons of the quadriceps angle of college-aged men and women in the supine and standing positions. Am J Sports Med. 1992;20(2):208-211;doi:10.1177/036354659202000220.

39. Fabry G, Cheng LX, Molenaers G. Normal and abnormal torsional development in children. Clin Orthop Relat Res. 1994;302:22-26.

40. Messier SP, Davis SE, Curl WW, Lowery RB, Pack RJ. Etiologic factors associated with patellofemoral pain in runners. Med Sci Sports Exerc. 1991;23(9):1008-1015; doi: 10.1249/00005768-199109000-00003.

41. Livingston LA, Mandigo JL. Bilateral within-subject $Q$ angle asymmetry in young adult females and males. In: Benghuzzi HA, Bajpai PK (eds.), Biomedical sciences instrumentation, vol. 33. Research Triangle Park: Instrument Society of America; 1997; 112-117. 